\title{
Atom Probe Tomography Evidence for Uniform Incorporation of Bi Across the Growth Front in $\mathrm{GaAs}_{1-\mathrm{x}} \mathrm{Bi}_{\mathbf{x}} / \mathbf{G a A s}$ Superlattice
}

\author{
Weixin Chen ${ }^{\mathrm{a},}$, Paul A. Ronsheim ${ }^{\mathrm{b}}$, Adam W. Wood ${ }^{\mathrm{a}}$, Kamran Forghani, \\ Yingxin Guan ${ }^{\mathrm{a}}$, Thomas F. Kuech ${ }^{\mathrm{a}, \mathrm{c}}$, and Susan E. Babcock ${ }^{\mathrm{a}}$ \\ ${ }^{a}$ Department of Materials Science and Engineering, University of Wisconsin-Madison, Madison, Wisconsin, \\ 53706, USA \\ ${ }^{\mathrm{b}}$ PAR Technical Consulting, LLC, Barneveld, Wisconsin, 53507, USA \\ ${ }^{\mathrm{c}}$ Department of Chemical and Biological Engineering, University of Wisconsin-Madison, Madison, Wisconsin, \\ 53706, USA \\ *Corresponding author. Email address: wchen254@wisc.edu (Weixin Chen)
}

The three-dimensional distribution of $\mathrm{Bi}$ atoms in a $\mathrm{GaAs}_{1-\mathrm{x}} \mathrm{Bi}_{\mathrm{x}} / \mathrm{GaAs}$ superlattice grown by metalorganic vapor phase epitaxy (MOVPE) was studied using atom probe tomography (APT). The Bi distribution in the growth direction deduced from APT agreed quantitatively with the complex Bi concentration profile that was discovered using high-angle annular dark-field scanning transmission electron microscopy in a previous study. More importantly, APT revealed the Bi atom distribution in the growth planes at near atomic resolution. Bi nearest neighbor distribution and concentration frequency distribution analysis of the APT data indicated a statistically random distribution of $\mathrm{Bi}$ atoms in 1-2 $\mathrm{nm}$ thick layers oriented perpendicular to the growth direction. These results provide evidence that $\mathrm{Bi}$ is incorporated homogeneously across the growth front even when the concentration profile in the growth direction is complex. They also suggest that MOVPE growth conditions can promote uniform Bi distribution within $\mathrm{GaAs}_{1-\mathrm{x}} \mathrm{Bi}_{\mathrm{x}}$ layers, opening a path for application of these materials in the optoelectronic devices for which they show much promise.

Keywords:

A1. Characterization

A1. Atom probe tomography

A3. Metalorganic vapor phase epitaxy

A3. Superlattices

B1. Bismuth compounds

B2. Semiconducting III-V materials 


\section{Introduction}

Solid solutions in the ternary semiconductor alloy system $\mathrm{GaAs}_{1-\mathrm{x}} \mathrm{Bi}_{\mathrm{x}}$ show promise to enable new and improved optoelectronic devices [1-3] due to the sensitivity of their electronic structure and properties to the concentration of $\mathrm{Bi}$. For example, a small change in $\mathrm{Bi}$ solute concentration induces a large change in valence band structure, which results in a large reduction of band gap [4-6] and offers intriguing band line-ups at heterointerfaces with other semiconductors. However, Bi substitution on the As sites is inhibited by the large difference in electronegativity and covalent radius between $\mathrm{As}$ and $\mathrm{Bi}$ atoms, leading to a vanishingly small solubility limit $\left(x=5.2 \times 10^{-5}\right)$ under typical growth conditions [7]. Single-phase $\mathrm{GaAs}_{1-\mathrm{x}} \mathrm{Bi}_{\mathrm{x}}$ thin films have been grown by both metalorganic vapor phase epitaxy (MOVPE) [8,9] and molecular beam epitaxy (MBE) [10-12], but phase separation, Bi surface segregation, and compositional inhomogeneity are often observed in those epitaxial layers [13]. Further design and optimization of growth methods and conditions are necessary to produce high quality films with higher $\mathrm{Bi}$ concentrations, uniform $\mathrm{Bi}$ distribution, abrupt compositional interfaces, and microstructural stability during post-growth processing and device operation. Given the strong effect of $\mathrm{Bi}$ on the band gap, Bi concentration variation can cause substantial local variation in the optoelectronic properties [5, 14]. In order to grow high-quality epitaxial $\mathrm{GaAs}_{1-\mathrm{x}} \mathrm{Bi}_{\mathrm{x}}$ with uniform $\mathrm{Bi}$ concentration, we need to understand how $\mathrm{Bi}$ atoms are incorporated in the growth front and subsequently distributed in the grown films.

X-ray diffraction (XRD) and high-angle annular dark-field (HAADF) scanning transmission electron microscopy (STEM) have been used previously [15] to investigate the $\mathrm{Bi}$ concentration profile in the $\mathrm{GaAs}_{1-}$ ${ }_{x} \mathrm{Bi}_{\mathrm{x}} / \mathrm{GaAs}$ superlattice investigated in this study. The XRD method allows deduction of the Bi concentration in the layers that comprise the superlattice, but it is based on fitting the diffraction pattern to a simulation for which the generic shape of the concentration profile is an input. Often the square wave form of a perfect superlattice is assumed. In the previous study [15], the shape of the concentration profile was deduced from HAADF-STEM ("Z-contrast") images, rather than assumed, to refine the concentration determination. In parallel, the total $\mathrm{Bi}$ content of the structure deduced from XRD was used to convert the intensity distribution in the STEM images to corresponding Bi concentration values. The coupled XRD/STEM analyses provided a $\mathrm{Bi}$ concentration profile in the growth direction with near atomic scale resolution. However possible composition variation in the direction of the electron beam, in this case within the growth plane, can be averaged out of HAADF STEM images and therefore is undetectable if the length scale is on the order of the sample thickness or less. Bi nanoclustering in epitaxial $\mathrm{GaAs}_{1-\mathrm{x}} \mathrm{Bi}_{\mathrm{x}}$ was found to be possible based on the quantitative analysis of an extracted two-dimensional (2D) map of Bi atoms from Z-contrast STEM images [16], but it is essentially based on a $2 \mathrm{D}$ projection of the composition of atomic columns. Thermal annealing has been shown to affect both the microstructure and optical properties of $\mathrm{GaAs}_{1-\mathrm{x}} \mathrm{Bi}_{\mathrm{x}}$ thin films. Bi-rich $\mathrm{GaAs}_{1-\mathrm{x}} \mathrm{Bi}_{\mathrm{x}}$, As clusters, and $\mathrm{Bi}$ clusters have been reported in the annealed $\mathrm{GaAs}_{1-\mathrm{x}} \mathrm{Bi}_{\mathrm{x}}$ layers $[17,18]$. Annealing also has lead to enhanced photoluminescence peak intensity in $\mathrm{GaAs}_{1-\mathrm{x}} \mathrm{Bi}_{\mathrm{x}}$ materials $[19,20]$. Therefore, direct three-dimensional (3D) measurements of composition and microstructure in $\mathrm{GaAs}_{1-\mathrm{x}} \mathrm{Bi}_{\mathrm{x}}$ are necessary to advance the 
understanding and development of $\mathrm{GaAs}_{1-\mathrm{x}} \mathrm{Bi}_{\mathrm{x}}$ materials for optoelectronic applications.

Atom probe tomography (APT) is a powerful materials analysis technique for $3 \mathrm{D}$ composition mapping at subnanometer resolution. By combining spatial projection and time of flight mass spectroscopy, the $3 \mathrm{D}$ positions and the elemental identities of the atoms in the specimens can be reconstructed for quantitative analysis of local compositional and microstructural details. Pulsed laser APT has been applied to a wide range of materials, such as metals and metal alloys, semiconductors, ceramic and geological materials, and organic and biological materials [21]. APT studies of GaAs and GaAs-based materials have been reported as well [22-25]. This work investigated the $3 \mathrm{D} \mathrm{Bi}$ distribution in a $\mathrm{GaAs}_{1-\mathrm{x}} \mathrm{Bi}_{\mathrm{x}} / \mathrm{GaAs}$ superlattice using APT. The 3D atom mapping capability complements STEM investigation of the microstructure and composition. In particular, the lateral atomic distribution in the growth plane, which can be concealed in STEM images, is evident in APT. The $\mathrm{Bi}$ atom distribution in the growth planes was examined using standard APT cluster analysis methods.

\section{Materials and Methods}

The $\mathrm{GaAs}_{1-\mathrm{x}} \mathrm{Bi}_{\mathrm{x}} / \mathrm{GaAs}$ superlattice (Fig. 1(a)) was grown by MOVPE on a (l 001$)$ GaAs substrate at $390^{\circ} \mathrm{C}$, as described previously [9]. The Ga and Bi precursors were introduced into the reactor in asynchronous short pulses for growth of $\mathrm{GaAs}_{1-\mathrm{x}} \mathrm{Bi}_{\mathrm{x}}$ layers [9]. The growth procedure was designed to produce alternating discrete and compositionally uniform $\mathrm{GaAs}_{1-\mathrm{x}} \mathrm{Bi}_{\mathrm{x}}$ and $\mathrm{GaAs}$ layers, but in reality the $\mathrm{Bi}$ concentration profile along the growth direction deduced from STEM images [15] showed additional features due to the complex kinetics and surface chemistry in the growth front.
Sharp needle-shaped APT specimens were prepared by the focused ion beam method of lift-out and annular milling [26]. The final milling step was performed with a low-energy ion beam $(5 \mathrm{kV}, 20 \mathrm{pA})$ to reduce $\mathrm{Ga}$ ion implantation. The sharp needle-shaped APT specimens (shown in Fig. 1(b)) with the superlattice structure in the apex were less than $100 \mathrm{~nm}$ in initial diameter with a hemisphere-shaped surface. The superlattice reconstructions and the analysis results were completely consistent across the three APT specimens investigated in this study.

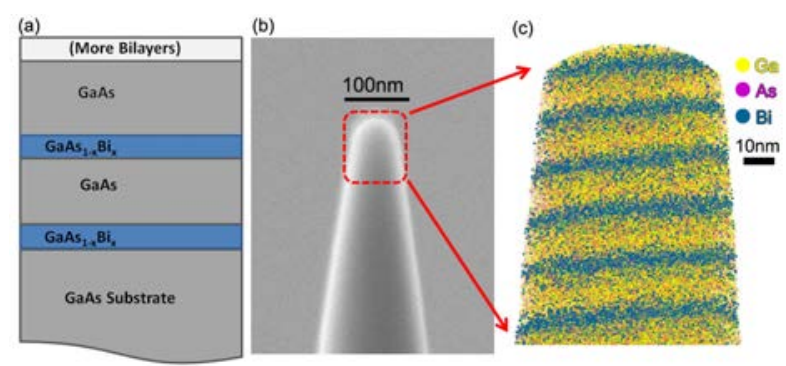

Fig. 1. (a) Schematic of the $\mathrm{GaAs}_{1-\mathrm{x}} \mathrm{Bi}_{\mathrm{x}} / \mathrm{GaAs}$ superlattice design; (b) secondary electron scanning electron microscope image of the sharp needle-shaped APT specimen with $\mathrm{GaAs}_{1-\mathrm{x}} \mathrm{Bi}_{\mathrm{x}} / \mathrm{GaAs}$ superlattice structure captured in the apex; (c) APT atom map showing $10 \%$ of Ga atoms, $10 \%$ of As atoms, and $100 \%$ of $\mathrm{Bi}$ atoms.

The APT experiments were conducted in a Cameca 3000X Si local electrode atom probe in laser pulsing mode. The results presented below were obtained at the evaporation rate of 0.005 ions per pulse with laser energy of $8 \mathrm{pJ}$, pulse frequency of $250 \mathrm{kHz}$, specimen temperature of $30 \mathrm{~K}$, and vacuum pressure of $2 \times 10^{-11}$ Torr. The laser energy was set as low as possible to reduce the thermally activated atom migration on the surface that has been reported for GaAs [27]. The voltage varied from $3 \mathrm{kV}$ to $4 \mathrm{kV}$ over the course of the experiment. The reconstruction and analyses were 
performed in IVAS ${ }^{\mathrm{TM}}$ 3.6.6 software. The scale and geometry of the reconstructed volume was based on the voltage evolution of the field evaporation. The spacing between the layers deduced from STEM images [15] also was considered as correlative information for the reconstructions. All of the significant peaks in the APT mass spectrum were identified and ranged for the reconstructions. Arsenic atoms field-evaporated as both As ions and molecular ions such as $\mathrm{As}_{2}{ }^{+}, \mathrm{As}_{3}{ }^{+}, \mathrm{As}_{3}{ }^{2+}$, $\mathrm{As}_{4}{ }^{+}$, as observed in other studies [24]. Also as observed in previous studies [25], the Ga:As atomic ratio in GaAs was measured to be slightly larger than 1 . However, no Bi-containing molecular ions were found in the mass spectra. Bi field-evaporated only as $\mathrm{Bi}^{+}$and $\mathrm{Bi}^{2+}$, therefore allowing accurate location of $\mathrm{Bi}$ atoms in spite of the lack of high resolution in locating and counting As atoms. The $\mathrm{Bi}$ concentration values reported in this study, all defined as the $\mathrm{x}$ value in $\mathrm{GaAs}_{1-\mathrm{x}} \mathrm{Bi}_{\mathrm{x}}$, agreed well with those deduced in the previous study by coupled XRD and HAADF imaging [15].

\section{Results and Discussion}

Fig. 1(c) shows the reconstructed atom map of the $\mathrm{GaAs}_{1-\mathrm{x}} \mathrm{Bi}_{\mathrm{x}} / \mathrm{GaAs}$ superlattice. $10 \%$ of the detected $\mathrm{Ga}$ atoms, $10 \%$ of the detected As atoms, and $100 \%$ of the detected $\mathrm{Bi}$ atoms are shown in the atom map for a better visualization of the structure. The $3 \mathrm{D} \mathrm{Bi}$ atom map is shown in a video in Supplementary Materials. Fig. 2 shows the Bi concentration profile $(1 \mathrm{~nm}$ bin width) along the growth direction. The vertical error bars based on the statistical counting errors are shown in a figure in Supplementary Materials. The maximum $\mathrm{Bi}$ concentration is around $3 \%\left(\mathrm{GaAs}_{1-\mathrm{x}} \mathrm{Bi} \mathrm{i}_{\mathrm{x}}, \mathrm{x}=3 \%\right)$. The minimum $\mathrm{Bi}$ concentration is about $0.05 \%$ located in the layers that were intended to be pure GaAs. The small $\mathrm{Bi}^{+}$peak that appears in the mass spectrum from the GaAs layers indicates that the measured $\mathrm{Bi}$ concentration of about $0.05 \%$ is a real presence of $\mathrm{Bi}$ and not just a consequence of background in the mass spectrum. Furthermore, the small peaks in $\mathrm{Bi}$ concentration that precede the $\mathrm{GaAs}_{1-\mathrm{x}} \mathrm{Bi}_{\mathrm{x}}$ layers, indicated by the arrows in Fig. 2, are about $0.5 \%$ in $\mathrm{Bi}$ concentration. These pre-peaks in $\mathrm{Bi}$ concentration have been related to the delayed onset of $\mathrm{Bi}$ incorporation during the growth [15]. As shown in Fig. 3 , the Bi concentration values and layer thickness from APT are in quantitative agreement with those deduced from the Z-contrast STEM images [15], indicating that both APT and HAADF-STEM techniques can provide accurate measurement of $\mathrm{Bi}$ concentration profile in nanometer scale in the growth direction. The upward slope from left to right in the concentration profile (Fig. $3(d)$ ) is likely due to the thickness gradient of the sample used for STEM imaging.

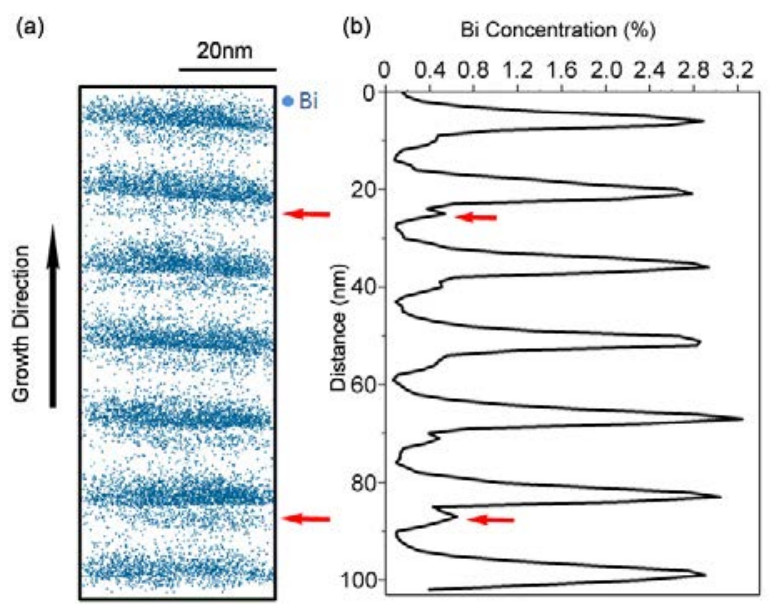

Fig. 2. (a) Side view of the reconstructed $\mathrm{Bi}$ atom map of the $\mathrm{GaAs}_{1-}$ ${ }_{x} \mathrm{Bi}_{\mathrm{x}} / \mathrm{GaAs}$ superlattice structure (3D version is shown in Supplementary Material); (b) Bi 1D concentration profile (1 nm bin width) along the growth direction deduced from APT. Arrows indicate the unintended pre-peaks under the $\mathrm{GaAs}_{1-\mathrm{x}} \mathrm{Bi}_{\mathrm{x}}$ layers. 


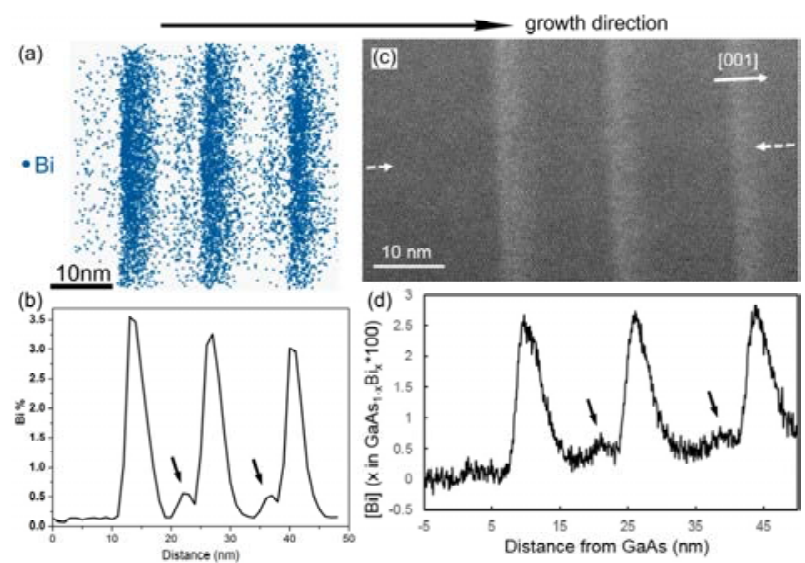

Fig. 3. (a) APT Bi atom map for the first three $\mathrm{GaAs}_{1-\mathrm{x}} \mathrm{Bi}_{\mathrm{x}}$ layers; (b) corresponding APT Bi concentration profile in the growth direction; (c) HAADF-STEM image for the first three $\mathrm{GaAs}_{1-\mathrm{x}} \mathrm{Bi}_{\mathrm{x}}$ layers; (d) corresponding $\mathrm{Bi}$ concentration profile in the growth direction deduced from HAADF-STEM imaging. Arrows indicate the prepeaks under the $\mathrm{GaAs}_{1-\mathrm{x}} \mathrm{Bi}_{\mathrm{x}}$ layers. (c) and (d) are reproduced with permission from APL Mater. 3, 036108 (2015).

With the 3D atomic imaging capability of APT, the homogeneity of $\mathrm{Bi}$ incorporation within the growth planes was studied using the statistical analysis tools. For the in-plane $\mathrm{Bi}$ atom distribution analysis, $\mathrm{GaAs}_{1-}$ ${ }_{x} \mathrm{Bi}_{\mathrm{x}}$ layers (Fig. 4(a)) with thickness of 1-2 nm were extracted from the reconstruction. Choosing a thin layer avoids convoluting the $\mathrm{Bi}$ concentration variation along the growth direction with that in the growth plane. Exploration of lateral homogeneity also requires the analyzed layer to be thin relative to the nearest neighbor distance. Fig. 4(b) is a top view (2D projection) of the thin $\mathrm{GaAs}_{1-\mathrm{x}} \mathrm{Bi}_{\mathrm{x}}$ layer, which shows the in-plane $\mathrm{Bi}$ atom distribution vividly. It is difficult to draw conclusions about the uniformity of $\mathrm{Bi}$ distribution by observation of the atom map alone, although the map lacks strong evidence of $\mathrm{Bi}$ clustering. To assess the presence of clustering quantitatively, $\mathrm{K}^{\text {th }}$ nearest neighbor distribution (NND) analysis was conducted in the $\mathrm{GaAs}_{1-\mathrm{x}} \mathrm{Bi}_{\mathrm{x}}$ layers. $\mathrm{K}^{\text {th }}$ NND examines the distribution of interatomic separations between each $\mathrm{Bi}$ atom and its $\mathrm{K}^{\text {th }}$ nearest-neighbor $\mathrm{Bi}$ atom. The NND approach has been developed and used for finding clusters and precipitates in APT data [28-32].

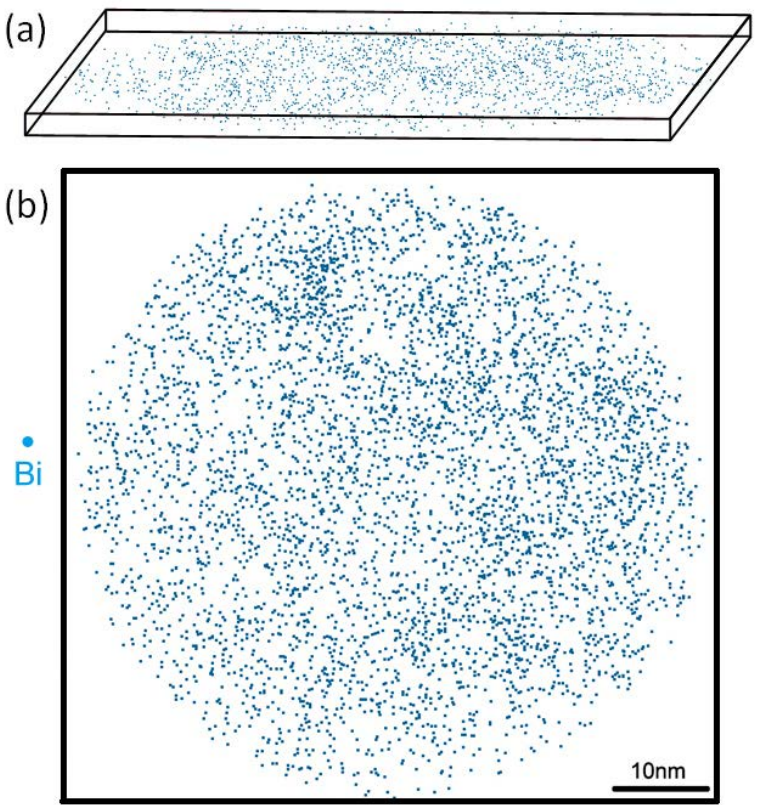

Fig. 4. 3D Bi atom map by APT offers the lateral distribution information. (a) A thin $\mathrm{GaAs}_{1-\mathrm{x}} \mathrm{Bi}_{\mathrm{x}}$ layer selected for in-plane $\mathrm{Bi}$ atom distribution analysis; (b) a top view (2D projection) of the in-plane $\mathrm{Bi}$ atom distribution in the layer shown in (a).

On the NND plots (Fig. 5), the horizontal axis, d-pair, is a possible distance between a $\mathrm{Bi}$ atom and its $\mathrm{K}^{\text {th }}$ nearest neighbor $\mathrm{Bi}$ atom. The vertical axis is the number of times the distance is observed throughout the analysis. NND histograms from the experimental data set are plotted together with those from a random comparator. The random comparator is a simulated data set for which the positions of the atoms detected in the experiment are preserved, but each position is assigned an elemental identity randomly while the measured composition in the experimental data set is maintained 
$[28,30]$. Superposition of the NND from the experiment and comparator indicates that $\mathrm{Bi}$ atoms are randomly distributed. If $\mathrm{Bi}$ were distributed unevenly with clustering, the two distributions would be distinct.

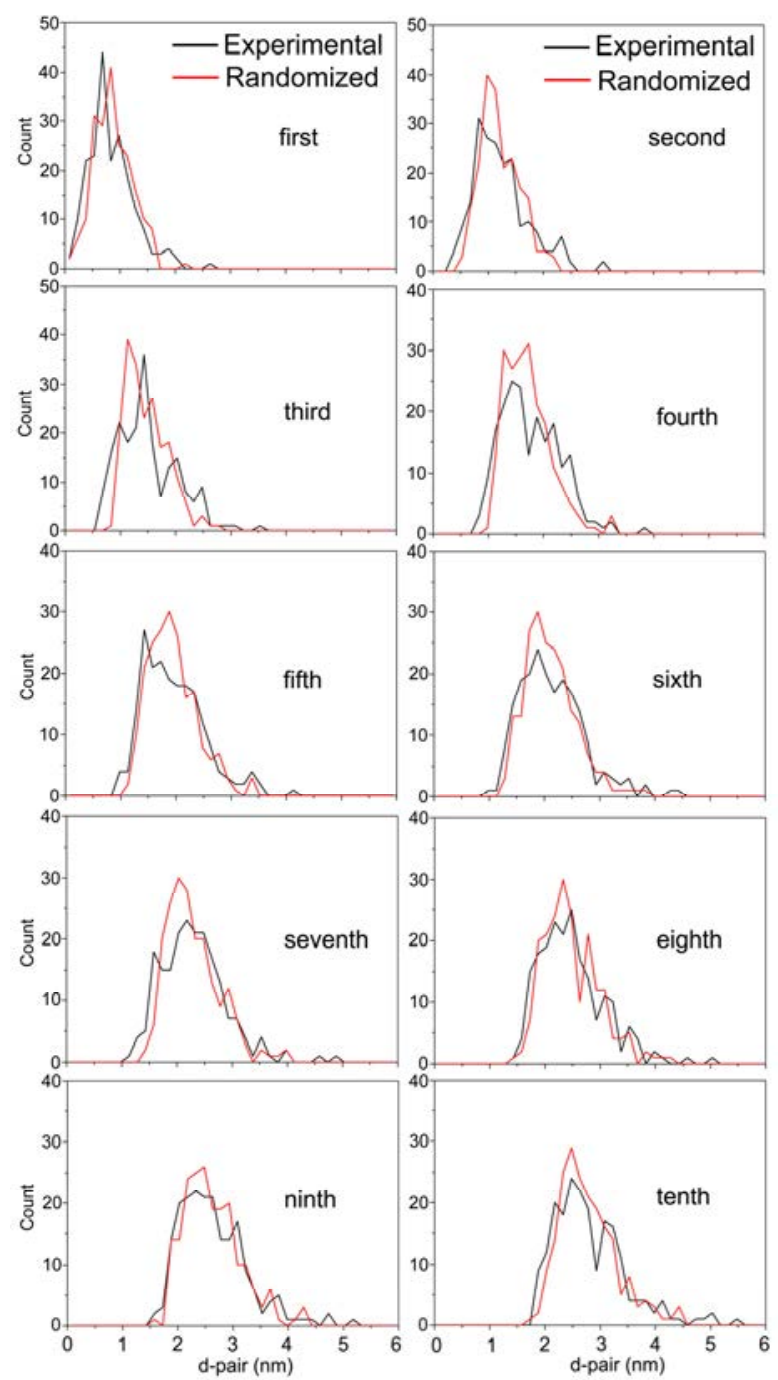

Fig. 5. Bi $\mathrm{K}^{\text {th }}$ NND histograms with different orders of neighbors (from the first order to the tenth order) in a $1 \mathrm{~nm}$ thick $\mathrm{GaAs}_{1-\mathrm{x}} \mathrm{Bi}_{\mathrm{x}}$ layer.

Bi NND was examined with a series of increasing orders, $\mathrm{K}^{\text {th }}$, of neighbors to probe the uniformity of $\mathrm{Bi}$ distribution in a comprehensive way. As shown in Fig.
5, experimental NND histograms from the first order to the tenth order all show no significant deviation from the random comparators. The NND analysis from all of the $\mathrm{GaAs}_{1-\mathrm{x}} \mathrm{Bi}_{\mathrm{x}}$ layers in the superlattice showed this same behavior. These analyses strongly suggest that $\mathrm{Bi}$ atoms are distributed homogeneously within the growth planes in the as-deposited $\mathrm{GaAs}_{1-\mathrm{x}} \mathrm{Bi}_{\mathrm{x}} / \mathrm{GaAs}$ superlattice.

Fig. 6 shows the $\mathrm{Bi}$ concentration frequency distribution (voxel size of 200 atoms) in a $2 \mathrm{~nm}$ thick $\mathrm{GaAs}_{1-\mathrm{x}} \mathrm{Bi}_{\mathrm{x}}$ layer. Again, the thin layer was chosen to avoid convolution of $\mathrm{Bi}$ concentration variation along the growth direction with possible lateral variation. For this analysis, the volume of interest is divided into discrete voxels and the $\mathrm{Bi}$ atomic concentration in each voxel is measured. The binomial distribution that is expected for randomly distributed $\mathrm{Bi}$ is plotted in red for comparison (Fig. 6). The experimental data closely follow the binomial distribution, which also indicates a homogenous distribution of $\mathrm{Bi}$ atoms in the growth plane. Concentration frequency distribution analysis was performed for all the $\mathrm{GaAs}_{1-\mathrm{x}} \mathrm{Bi}_{\mathrm{x}}$ layers in the superlattice, and each analysis yielded the same result.

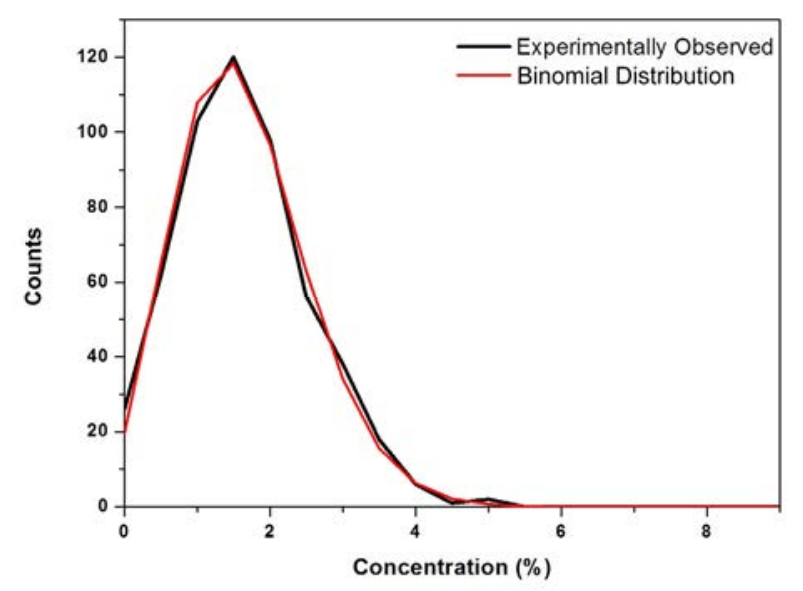

Fig. 6. Bi concentration frequency distribution in a $2 \mathrm{~nm}$ thick $\mathrm{GaAs}_{1-}$ ${ }_{\mathrm{x}} \mathrm{Bi}_{\mathrm{x}}$ layer. 
The Bi distribution in the growth direction can be non-uniform in MOVPE-grown $\mathrm{GaAs}_{1-\mathrm{x}} \mathrm{Bi}_{\mathrm{x}}$ materials, especially when trimethyl bismuth is used as a precursor. This effect is likely due to complicated decomposition and reaction processes of the metalorganic precursors [15, 33]. The current work explored whether in-plane $\mathrm{Bi}$ inhomogeneity is induced as well and concluded it is not. More recent growth studies have identified precursors, for example triethyl bismuth [34], that appear to decompose more quickly on the surface and lead to less complex composition profiles in the growth direction. These results suggest that further optimization of precursor selection and growth parameters can lead to uniformly distributed Bi in $3 \mathrm{D}$ within the $\mathrm{GaAs}_{1-\mathrm{x}} \mathrm{Bi}_{\mathrm{x}}$ layers.

The APT observation of homogeneous $\mathrm{Bi}$ distribution in the growth plane is not surprising. $\mathrm{Bi}$ atoms are expected to be mobile on the growth surface due to high surface diffusivity. However, the location of their incorporation is likely influenced by the local strains surrounding $\mathrm{Bi}$ atoms that already reside in the film. Such incorporation behavior would lead to homogeneously distributed $\mathrm{Bi}$ in the growth plane. Moreover, in the bulk of the growing film, the low growth temperature inhibits diffusion of $\mathrm{Bi}$ atoms once they are buried, thus inhibiting cluster formation as well.

\section{Conclusions}

In summary, APT was used to generate $3 \mathrm{D}$ maps of $\mathrm{Bi}$ atom positions in a $\mathrm{GaAs}_{1-\mathrm{x}} \mathrm{Bi}_{\mathrm{x}} / \mathrm{GaAs}$ superlattice. The details in the $\mathrm{Bi}$ concentration profile along the growth direction, determined by HAADF-STEM imaging in a previous study, were also apparent in the APT data. Most importantly, APT atomic mapping and statistical analysis strongly indicated that $\mathrm{Bi}$ is distributed homogeneously within the growth plane in the as-deposited $\mathrm{GaAs}_{1-\mathrm{x}} \mathrm{Bi}_{\mathrm{x}} / \mathrm{GaAs}$ superlattice. The results suggest that MOVPE growth conditions can be optimized to produce uniform $\mathrm{Bi}$ incorporation across the growth front.

\section{Acknowledgments}

This research was primarily supported by National Science Foundation through University of Wisconsin Materials Research Science and Engineering Center (DMR-1121288). The authors also acknowledge the instrumentation support by the Materials Science Center at University of Wisconsin-Madison.

\section{References}

[1] K. Alberi, O.D. Dubon, W. Walukiewicz, K.M. Yu, K. Bertulis, A. Krotkus, Valence band anticrossing in $\mathrm{GaBi}_{\mathrm{X}} \mathrm{As}_{1-\mathrm{x}}$, Appl. Phys. Lett., 91 (2007) 051909.

[2] K. Bertulis, A. Krotkus, G. Aleksejenko, V. Pačebutas, R. Adomavičius, G. Molis, S. Marcinkevičius, GaBiAs: A material for optoelectronic terahertz devices, Appl. Phys. Lett., 88 (2006) 201112.

[3] B. Fluegel, S. Francoeur, A. Mascarenhas, S. Tixier, E.C. Young, T. Tiedje, Giant Spin-Orbit Bowing in $\mathrm{GaAs}_{1-\mathrm{x}} \mathrm{Bi}_{\mathrm{x}}$, Phys. Rev. Lett., 97 (2006) 067205.

[4] S. Francoeur, M.-J. Seong, A. Mascarenhas, S. Tixier, M. Adamcyk, T. Tiedje, Band gap of $\mathrm{GaAs}_{1-\mathrm{x}} \mathrm{Bi}_{\mathrm{x}}, 0<\mathrm{x}<3.6 \%$, Appl. Phys. Lett., 82 (2003) 3874-3876.

[5] M. Masnadi-Shirazi, R.B. Lewis, V. BahramiYekta, T. Tiedje, M. Chicoine, P. Servati, Bandgap and optical absorption edge of $\mathrm{GaAs}_{1-\mathrm{x}} \mathrm{Bi}_{\mathrm{x}}$ alloys with $0<\mathrm{x}$ $<17.8 \%$, J. Appl. Phys., 116 (2014) 223506.

[6] R. Kudrawiec, J. Kopaczek, M.P. Polak, P. Scharoch, M. Gladysiewicz, J. Misiewicz, R.D. Richards, F. Bastiman, J.P.R. David, Experimental and theoretical studies of band gap alignment in $\mathrm{GaAs}_{1_{-\mathrm{x}}} \mathrm{Bi}_{\mathrm{x}} / \mathrm{GaAs}$ quantum wells, J. Appl. Phys., 116 (2014) 233508.

[7] H. Jacobsen, B. Puchala, T.F. Kuech, D. Morgan, $A b$ initio study of the strain dependent thermodynamics of Bi doping in GaAs, Phys. Rev. B, 86 (2012) 085207. [8] P. Ludewig, N. Knaub, W. Stolz, K. Volz, MOVPE growth of $\mathrm{Ga}(\mathrm{AsBi}) / \mathrm{GaAs}$ multi quantum well structures, J. Cryst. Growth, 370 (2013) 186-190.

[9] K. Forghani, Y. Guan, A.W. Wood, A. Anand, S.E. Babcock, L.J. Mawst, T.F. Kuech, Self-limiting growth when using trimethyl bismuth (TMBi) in the metal- 
organic vapor phase epitaxy (MOVPE) of $\mathrm{GaAs}_{1-\mathrm{y}} \mathrm{Bi}_{\mathrm{y}}$, J. Cryst. Growth, 395 (2014) 38-45.

[10] J. Li, T.-H. Kim, K. Forghani, W. Jiao, W. Kong, K. Collar, T.F. Kuech, A.S. Brown, Growth of $\mathrm{GaAs}_{1-\mathrm{x}} \mathrm{Bi}_{\mathrm{x}}$ by molecular beam epitaxy: Trade-offs in optical and structural characteristics, J. Appl. Phys., 116 (2014) 043524.

[11] D. Fan, P.C. Grant, S.-Q. Yu, V.G. Dorogan, X. Hu, Z. Zeng, C. Li, M.E. Hawkridge, M. Benamara, Y.I. Mazur, G.J. Salamo, S.R. Johnson, Z.M. Wang, MBE grown GaAsBi/GaAs double quantum well separate confinement heterostructures, Journal of Vacuum Science \& Technology B: Microelectronics and Nanometer Structures, 31 (2013) 03C105.

[12] S. Tixier, M. Adamcyk, T. Tiedje, S. Francoeur, A. Mascarenhas, P. Wei, F. Schiettekatte, Molecular beam epitaxy growth of $\mathrm{GaAs}_{1-\mathrm{x}} \mathrm{Bi}_{\mathrm{x}}$, Appl. Phys. Lett., 82 (2003) 2245-2247.

[13] G. Vardar, S.W. Paleg, M.V. Warren, M. Kang, S. Jeon, R.S. Goldman, Mechanisms of droplet formation and $\mathrm{Bi}$ incorporation during molecular beam epitaxy of GaAsBi, Appl. Phys. Lett., 102 (2013) 042106.

[14] C. Gogineni, N.A. Riordan, S.R. Johnson, X. Lu, T. Tiedje, Disorder and the Urbach edge in dilute bismide GaAsBi, Appl. Phys. Lett., 103 (2013) 041110. [15] A.W. Wood, Y. Guan, K. Forghani, A. Anand, T.F. Kuech, S.E. Babcock, Unexpected bismuth concentration profiles in metal-organic vapor phase epitaxy-grown $\mathrm{Ga}(\mathrm{As} 1-\mathrm{xBix}) / \mathrm{GaAs}$ superlattices revealed by Z-contrast scanning transmission electron microscopy imaging, APL Materials, 3 (2015) 036108.

[16] D.L. Sales, E. Guerrero, J.F. Rodrigo, P.L. Galindo, A. Yáñez, M. Shafi, A. Khatab, R.H. Mari, M. Henini, S. Novikov, M.F. Chisholm, S.I. Molina, Distribution of bismuth atoms in epitaxial GaAsBi, Appl. Phys. Lett., 98 (2011) 101902.

[17] J. Puustinen, M. Wu, E. Luna, A. Schramm, P. Laukkanen, M. Laitinen, T. Sajavaara, M. Guina, Variation of lattice constant and cluster formation in GaAsBi, J. Appl. Phys., 114 (2013) 243504.

[18] M. Wu, E. Luna, J. Puustinen, M. Guina, A. Trampert, Formation and phase transformation of $\mathrm{Bi}$ containing QD-like clusters in annealed $\mathrm{GaAsBi}$, Nanotechnology, 25 (2014) 205605.

[19] P.C. Grant, D. Fan, A. Mosleh, S.-Q. Yu, V.G. Dorogan, M.E. Hawkridge, Y.I. Mazur, M. Benamara, G.J. Salamo, S.R. Johnson, Rapid thermal annealing effect on $\mathrm{GaAsBi} / \mathrm{GaAs}$ single quantum wells grown by molecular beam epitaxy, Journal of Vacuum Science \& Technology B: Microelectronics and Nanometer Structures, 32 (2014) 02C119.

[20] A.R. Mohmad, F. Bastiman, C.J. Hunter, R. Richards, S.J. Sweeney, J.S. Ng, J.P.R. David, Effects of rapid thermal annealing on GaAs1-xBix alloys, Appl. Phys. Lett., 101 (2012) 012106.
[21] T.F. Kelly, D.J. Larson, Atom Probe Tomography 2012, Ann. Rev. Mater. Res., 42 (2012) 1-31.

[22] M. Müller, A. Cerezo, G.D.W. Smith, L. Chang, S.S.A. Gerstl, Atomic scale characterization of buried $\mathrm{In}_{\mathrm{x}} \mathrm{Ga}_{1-\mathrm{x}} \mathrm{As}$ quantum dots using pulsed laser atom probe tomography, Appl. Phys. Lett., 92 (2008) 233115.

[23] A.J. Martin, J. Hwang, E.A. Marquis, E. Smakman, T.W. Saucer, G.V. Rodriguez, A.H. Hunter, V. Sih, P.M. Koenraad, J.D. Phillips, J. Millunchick, The disintegration of GaSb/GaAs nanostructures upon capping, Appl. Phys. Lett., 102 (2013) 113103.

[24] S. Du, T. Burgess, B. Gault, Q. Gao, P. Bao, L. Li, X. Cui, W. Kong Yeoh, H. Liu, L. Yao, A.V. Ceguerra, H. Hoe Tan, C. Jagadish, S.P. Ringer, R. Zheng, Quantitative dopant distributions in GaAs nanowires using atom probe tomography, Ultramicroscopy, 132 (2013) 186-192.

[25] A.M. Beltran, E.A. Marquis, A.G. Taboada, J.M. Ripalda, J.M. Garcia, S.I. Molina, Three dimensional atom probe imaging of $\mathrm{GaAsSb}$ quantum rings, Ultramicroscopy, 111 (2011) 1073-1076.

[26] K. Thompson, D. Lawrence, D.J. Larson, J.D. Olson, T.F. Kelly, B. Gorman, In situ site-specific specimen preparation for atom probe tomography, Ultramicroscopy, 107 (2007) 131-139.

[27] B. Gault, F. Danoix, K. Hoummada, D. Mangelinck, H. Leitner, Impact of directional walk on atom probe microanalysis, Ultramicroscopy, 113 (2012) 182-191.

[28] L.T. Stephenson, M.P. Moody, P.V. Liddicoat, S.P. Ringer, New Techniques for the Analysis of FineScaled Clustering Phenomena within Atom Probe Tomography (APT) Data, Microsc. Microanal., 13 (2007) 448-463.

[29] T. Philippe, F. De Geuser, S. Duguay, W. Lefebvre, O. Cojocaru-Miredin, G. Da Costa, D. Blavette, Clustering and nearest neighbour distances in atom-probe tomography, Ultramicroscopy, 109 (2009) 1304-1309.

[30] R.K. Marceau, L.T. Stephenson, C.R. Hutchinson, S.P. Ringer, Quantitative atom probe analysis of nanostructure containing clusters and precipitates with multiple length scales, Ultramicroscopy, 111 (2011) 738-742.

[31] F. Tang, T. Zhu, F. Oehler, W.Y. Fu, J.T. Griffiths, F.C.P. Massabuau, M.J. Kappers, T.L. Martin, P.A.J. Bagot, M.P. Moody, R.A. Oliver, Indium clustering in a-plane InGaN quantum wells as evidenced by atom probe tomography, Appl. Phys. Lett., 106 (2015) 072104.

[32] D.E. Perea, I. Arslan, J. Liu, Z. Ristanovic, L. Kovarik, B.W. Arey, J.A. Lercher, S.R. Bare, B.M. Weckhuysen, Determining the location and nearest neighbours of aluminium in zeolites with atom probe tomography, Nat Commun, 6 (2015) 7589. 
[33] T.F. Kuech, S.E. Babcock, L. Mawst, Growth Far from Equilibrium: Examples from III-V Semiconductors Applied Physics Reviews (unpublished), (2016).

[34] K. Forghani, Y. Guan, A. Wood, S. Babock, L. Mawst, T.F. Kuech, The Effect of the Bi Precursors, $(\mathrm{CH} 3) 3 \mathrm{Bi}$ and $(\mathrm{C} 2 \mathrm{H} 5) 3 \mathrm{Bi}$, on the Metal-Organic Vapor Phase Epitaxy of GaAs1-yBiy Films, Chem. Vapor. Depos., 21 (2015) 166-175. 